\title{
Exploration of Complex Dynamics for Cournot Oligopoly Game with Differentiated Products
}

\author{
S. S. Askar $\mathbb{D}^{1,2}$ Mona F. EL-Wakeel $\mathbb{D}^{1,3}$ and M. A. Alrodaini ${ }^{1,4}$ \\ ${ }^{1}$ Department of Statistics and Operations Researches, College of Science, King Saud University, P.O. Box 2455, \\ Riyadh 11451, Saudi Arabia \\ ${ }^{2}$ Department of Mathematics, Faculty of Science, Mansoura University, Mansoura 354516, Egypt \\ ${ }^{3}$ Higher Institute of Computers, Information and Management Technology, Tanta, Egypt \\ ${ }^{4}$ Department of Mathematics, College of Science, Al Jouf University, Al Jawf, Saudi Arabia
}

Correspondence should be addressed to S. S. Askar; s.e.a.askar@hotmail.co.uk

Received 5 June 2017; Revised 26 November 2017; Accepted 28 December 2017; Published 13 February 2018

Academic Editor: José Ángel Acosta

Copyright (C) 2018 S. S. Askar et al. This is an open access article distributed under the Creative Commons Attribution License, which permits unrestricted use, distribution, and reproduction in any medium, provided the original work is properly cited.

\begin{abstract}
This paper proposes a Cournot game organized by three competing firms adopting bounded rationality. According to the marginal profit in the past time step, each firm tries to update its production using local knowledge. In this game, a firm's preference is represented by a utility function that is derived from a constant elasticity of substitution (CES) production function. The game is modeled by a 3-dimensional discrete dynamical system. The equilibria of the system are numerically studied to detect their complex characteristics due to difficulty to get an explicit form for those equilibria. For the proposed utility function, some cases with different value parameters are considered. Numerical simulations are used to provide an experimental evidence for the complex behavior of the evolution of the system. The obtained results show that the system loses its stability due to different types of bifurcations.
\end{abstract}

\section{Introduction}

The oligopoly market is an efficient market that is dominated by a number of firms which offer and sell homogeneous or similar products. Such market includes two popular types of models, namely, Cournot (quantity decision) and Bertrand (price decision) models. In Cournot models, the way that firms control their production levels has a critical effect on market outputs. Conversely, in Bertrand models, firms select prices to be their strategic variables to optimize their profits $[1,2]$. Practically, the dynamic of an oligopoly game is complex, since each oligopolistic firm must consider both the consumers' behaviors and the reactions of all competitors [3]. A Cournot triopoly game is an oligopoly market with three players that are in conflict and there is no cooperation among them. The first idea of a Cournot oligopoly market came to light in 1838 by Cournot [4] who proposed the first formal oligopoly theory and treated such idea with naive expectations on which each player assumes the last taken values by competitors with no consideration of their prospected reactions in the future [3]. In general, players in an oligopoly market try to enhance their expected profit which in turn is based on matching among the marginal revenue and marginal cost. Furthermore, each player can adjust his output based on selecting his expectation rule from among various available ones such as local bounded rational, adaptive, and naive expectations $[3,5]$.

Puu [6] conducted some of the first investigations in such economic games and thus he has concluded that various complex dynamics could result from a Cournot duopoly such as the presence of attractors with a fractal dimension. Various efforts were exerted then to study the dynamics of oligopoly models with considering more firms and various amendments [7, 8]. Elsadany and Awad [9] and Askar [10] presented a duopoly Cournot game model with considering the bounded rationality and linear cost and demand functions. Another duopoly game model was studied by Bischi et al. [11], where firms of naive expectations decided their outputs based 
on the reaction functions. Such model was then improved by Agiza and Elsadany [12] to include two heterogeneous players: adaptive expectation player and bounded rational one. More improvements have been conducted in such model by Zhang et al. [13] based on considering nonlinear cost functions. The complexity of this model was investigated then by Matsumoto and Nonaka [14] with considering linear cost functions. Other studies have been proposed and discussed in literature. For instance, a Cournot duopoly game was studied by Yassen and Agiza [15], taking into account the delayed rationality. In recent years, it has been demonstrated that oligopolistic markets may have chaotic or cyclic behavior under some conditions [8, 16-18]. Elsadany [5] has studied the dynamics of a Cournot duopoly model such as stability and existence of bifurcations that are responsible for affecting the behavior of equilibrium points. The model behavior was studied using both Lyapunov exponents and bifurcation diagrams, where results showed that such model has a chaotic behavior when some parameters were changed. Askar [19] has studied the complex characteristics of a Cournot duopoly model with the use of a gradient rule. He also developed a generalized demand function and proposed that various dynamic behaviors emerged from the stability to chaos through bifurcations. Furthermore, Askar [20] has studied other Cournot duopoly games that depend on nonlinear demand functions. He proposed a model of two rational firms that compete and offer homogeneous commodities on which their equilibrium points, bifurcation, chaos, and stability were investigated.

In literature, there are few studies that handle the economic game of three competitors. It is a complicated game in comparison with the duopoly one. In such studies, the main concern is to study the complex dynamic characteristics of the game. For example, some complex dynamics of duopoly game were studied in $[8,21-25]$. In practice, such game is close to the economic reality and it is widely deployed in oligopoly. However, analyzing the dynamics of such game is a complex task. Therefore, various investigations were performed previously with considering three homogeneous players, such as the work performed by Puu [26] who considered three naive players. He has concluded that a triopoly game could have complex dynamics and cycles and chaos may happen. Agiza et al. [8] have improved the proposed Kopel Cournot duopoly game in [10] to be a triopoly one and have discussed the multistability of the game. Askar and Al-khedhairi [21] have modeled a dynamic Cournot triopoly game that is composed of three homogeneous bounded rational players using nonlinear difference equations. They have concluded that the change in some model parameters causes losing the Nash equilibrium stability and the occurrence of a complex chaotic behavior. In addition, high adjustment speed values have caused chaos and bifurcations in the system. Andaluz et al. [27] have considered a Cournot oligopoly model that includes three competitive companies that offer homogeneous goods. Tu and Wang [28] have presented a dynamic master-slave Cournot triopoly game model with homogeneous bounded normal players. They have analyzed the effects of changes in the adjustment speed parameters on the system dynamics. In addition, the parameters adjustment method was used to control the system's complicated behavior. Various studies and investigations were performed then on Cournot triopoly games considering heterogeneous players. For instance, a model of a Cournot triopoly game was proposed by Ma and Ji [29] with a square inverse demand. Such model was later investigated by Ji [30] considering heterogeneous players. Elabbasy et al. [25] have proposed a triopoly game with heterogeneous players in order to study its dynamical behaviors with linear cost function. Another model of a nonlinear triopoly game was proposed by Elabbasy et al. [31] using three heterogeneous players, namely, naïve, bounded rational, and adaptive players. Askar and Alshamrani [32] have studied four different models, namely, cooperative Cournot triopoly, rational Bertrand triopoly, rational Cournot triopoly, and Puu triopoly, based on a quantity competition. The Nash equilibrium corresponding to each game was calculated. Inclusive theoretical and numerical studies concerning the stability of fixed points were conducted.

Other economic games in which prices are the main variables were studied in literature. For instance, Bertrand duopoly models were investigated by Brianzoni et al. [33], Zhao and Zhang [34], and Fanti et al. [35] depending on differentiated products. They have discussed that the degree of products differentiation had a major impact on the sale quantity and price. Bertrand duopoly model was investigated by Zhang et al. [36] depending on the price competition with bounded rationality. Peng [37] and Peng et al. [38] have introduced other Bertrand models in order to study and assess complexity of the model. Zhang and Wang [39] and Yali [40] have also investigated the complexity of such models, in which the bounded rationality of marginal costs and synchronization were considered. A Bertrand triopoly model was developed by Sun and Ma [1], in which the bounded rational expectations were considered and both the presence and local stability of the Nash equilibrium were studied. Furthermore, Sun and Ma [41] have introduced a Bertrand triopoly model using nonlinear demand functions. $\mathrm{Ma}$ and $\mathrm{Wu}[42]$ have studied the effect of delayed decision on the stability of a Bertrand triopoly model. They have found that there was no relation between the system stability and the time delay of decision-makers.

In economic market, there is also another kind of strategic variables which is a mix between price and quantity variables, in which the resultant game by such kind of variables is known as a Cournot-Bertrand game [32]. The competition of such game requires a specific differentiation degree among provided products by firms in order to prevent a firm with lower price from dominating the game market. Arya et al. [43], Hackner [44], Tremblay et al. [45], and Zanchettin [46] have investigated different types of Cournot-Bertrand games. The model of Cournot-Bertrand triopoly game is very close to real economy. It has been studied by several researchers in literature. For instance, C. H. Tremblay and V. J. Tremblay [47] have investigated the static properties of Nash equilibrium of a Cournot-Bertrand game with product differentiation. Naimzada and Tramontana [48] have studied the dynamic characteristics of a Cournot-Bertrand game, in which the product differentiation was considered with the use 
of linear cost function and linear demand. In [49], a masterslave Bertrand game has been proposed. In [29], a Cournot triopoly game was proposed based on a downstream firm and upstream firm. It was assumed that the downstream firm had a linear inverse demand function, while the upstream one had a nonlinear one, in which the cost functions were considered as nonlinear function. Tu et al. [50] have studied and investigated some complex characteristics of a CournotBertrand triopoly game. Moreover, there are some useful works that tackle some important characteristics of such games including risk and uncertainty aspects. Of those characteristics, the nonlinearity and fractals for records of tree-ring in China have been studied in [51]. Interaction among inducible defenses and herbivore outbreak of plants have been modeled and studied in [52]. The time delay has been studied in a herbivore-plant system using the interaction equations of diffusion [53]. The influences of Allee on a variety of population models have been studied in [54]. In [55], a model of reaction-diffusion has been introduced and discussed for plant interaction and herbivore under delay. The impact of colored noise on a spatial predator-prey model has been presented in [56]. For other useful works, the readers are advised to see [57-59].

Even though various efforts were performed in literature to study such games, more investigations need to be performed with a focus on assessing the nonlinear and complex performance of dynamic triopoly game models. Therefore, this paper investigates a dynamic Cournot triopoly game, in which differentiated goods are considered, and a utility function that is derived from CES. Our work in this paper is outlined as follows. In Section 2, the market utility structure of Cournot triopoly game with nonlinear demand function derived from CES and differentiated goods is proposed. Looking at the form of the utility function, Section 3 studies the dynamical behavior of game for several values of the parameter $\alpha$ which represents the degree of substitutability/differentiation among the commodities. Finally, some concluding remarks are drawn in Section 4.

\section{Market Utility}

The market considered within this paper consists of three competing firms whose strategies are the quantities they produce. Each firm's output is denoted by a nonnegative real value $q_{i}, i=1,2,3$. We assume that the consumer's preference is represented by the following utility CES function:

$$
U(\mathbf{q})=\sum_{i=1}^{3} q_{i}^{\alpha} \quad \mathbf{q}=\left(q_{1}, q_{2}, q_{3}\right) \in \mathbb{R}_{++}^{3}, 0<\alpha<1 .
$$

Since $\alpha<1$, it is easy to check that $U(\mathbf{q})$ is strictly concave. Therefore, it is strictly quasi-concave and so has strict convex to the origin level curves. This means that setting the total differential $d U=0$ and $d q_{1}=0$ we get the marginal rate of technical substitution, MRTS $_{2,3}=-d q_{3} / d q_{2}=\left(q_{2} / q_{3}\right)^{\alpha-1}$, which is strictly convex to the origin. A similar procedure will produce MRTS $_{1,2}$ and MRTS ${ }_{1,3}$. This means that the consumer can substitute one input for another and continue to produce the same level of output. We assume also that the above utility function is governed by the following budget constraint:

$$
\sum_{j=1}^{3} p_{j} q_{j}=1
$$

The inverses demand function (see the Appendix) can be expressed as follows:

$$
p_{j}=\frac{q_{j}^{\alpha-1}}{\sum_{i=1}^{3} q_{i}^{\alpha}}, \quad j=1,2,3 .
$$

The case when $\alpha=1$ has been studied by Puu [22]. In addition, the duopoly game has been studied by Agliari et al. [60]. For $\alpha=0$, the market is dominated by three monopolistic firms. When $\alpha=1$, it means that the goods are indistinguishable and the consumer may handle them as identical. Lower values of this factor make the goods interchangeable but not identical. Within this paper, we highlight some values for the parameter $\alpha$.

\section{Dynamic Analysis of the Game}

The profit of the $i$ th firm is defined as follows:

$$
\Pi_{i}\left(q_{i}\right)=q_{i} p_{i}-C_{i}\left(q_{i}\right), \quad i=1,2,3,
$$

where $C_{i}\left(q_{i}\right)$ defines the cost of the quantity produced and $p_{i}$ refers to the price of the quantity in the market. It is assumed here that the firms use a cost function that is linear and takes the form

$$
C_{i}\left(q_{i}\right)=c_{i} q_{i}, \quad i=1,2,3,
$$

where $\partial C_{i}\left(q_{i}\right) / \partial q_{i}=c_{i}, i=1,2,3$, is called the marginal cost. Substituting (3) in (4) gives

$$
\Pi_{i}\left(q_{i}\right)=\frac{q_{i}^{\alpha}}{\sum_{i=1}^{3} q_{i}^{\alpha}}-c_{i} q_{i}, \quad i=1,2,3 .
$$

For each firm, maximizing the profit depends on the marginal profit. The marginal profit is calculated by taking the first partial derivative of the above profit as follows:

$$
\frac{\partial \Pi_{i}}{\partial q_{i}}=\frac{\alpha q_{i}^{\alpha-1}\left(\sum_{\substack{j=1 \\ j \neq i}}^{3} q_{j}^{\alpha}\right)}{\left(\sum_{i=1}^{3} q_{i}^{\alpha}\right)^{2}}-c_{i}, \quad i=1,2,3 .
$$

The above derivatives yield the best-reply function $r_{i}, i=$ $1,2,3$ (or reaction functions), as follows:

$$
\begin{aligned}
& q_{1}=r_{1}\left(q_{2}, q_{3}\right), \\
& q_{2}=r_{2}\left(q_{1}, q_{3}\right), \\
& q_{3}=r_{3}\left(q_{1}, q_{2}\right) .
\end{aligned}
$$


Solving those functions gives Nash equilibrium point for the game. Due to the nonlinearity of (7), the analytical expression for Nash point is so complicated and then some numerical assumptions are used. Now, a repeated Cournot triopoly game whose players are bounded rational is considered. The mechanism used to describe such game is called myopic adjustment mechanism (see, e.g., [3]) and is presented by the following equation:

$$
q_{i, t+1}=q_{i, t}+k_{i} \frac{\partial \Pi_{i}}{\partial q_{i}},
$$

where $k_{i}$ stands for the positive parameter or the adjustment speed of the $i$ th firm. Substituting (7) in (9) gives the following dynamical system:

$$
\begin{aligned}
& q_{1, t+1}=q_{1, t}+k_{1}\left[\frac{\alpha q_{1}^{\alpha-1}\left(q_{2}^{\alpha}+q_{3}^{\alpha}\right)}{\left(q_{1}^{\alpha}+q_{2}^{\alpha}+q_{3}^{\alpha}\right)^{2}}-c_{1}\right], \\
& q_{2, t+1}=q_{2, t}+k_{2}\left[\frac{\alpha q_{2}^{\alpha-1}\left(q_{1}^{\alpha}+q_{3}^{\alpha}\right)}{\left(q_{1}^{\alpha}+q_{2}^{\alpha}+q_{3}^{\alpha}\right)^{2}}-c_{2}\right], \\
& q_{3, t+1}=q_{3, t}+k_{3}\left[\frac{\alpha q_{3}^{\alpha-1}\left(q_{1}^{\alpha}+q_{2}^{\alpha}\right)}{\left(q_{1}^{\alpha}+q_{2}^{\alpha}+q_{3}^{\alpha}\right)^{2}}-c_{3}\right] .
\end{aligned}
$$

System (10) admits steady states that satisfy the conditions

$$
\begin{aligned}
& \alpha q_{1}^{\alpha-1}\left(q_{2}^{\alpha}+q_{3}^{\alpha}\right)-c_{1}\left(q_{1}^{\alpha}+q_{2}^{\alpha}+q_{3}^{\alpha}\right)^{2}=0, \\
& \alpha q_{2}^{\alpha-1}\left(q_{1}^{\alpha}+q_{3}^{\alpha}\right)-c_{2}\left(q_{1}^{\alpha}+q_{2}^{\alpha}+q_{3}^{\alpha}\right)^{2}=0, \\
& \alpha q_{3}^{\alpha-1}\left(q_{1}^{\alpha}+q_{2}^{\alpha}\right)-c_{3}\left(q_{1}^{\alpha}+q_{2}^{\alpha}+q_{3}^{\alpha}\right)^{2}=0 .
\end{aligned}
$$

Simple calculations reduce the algebraic system given in (11) to the following:

$$
\begin{aligned}
& c_{2} q_{1}^{\alpha-1}\left(q_{2}^{\alpha}+q_{3}^{\alpha}\right)-c_{1} q_{2}^{\alpha-1}\left(q_{1}^{\alpha}+q_{3}^{\alpha}\right)=0, \\
& c_{1} q_{3}^{\alpha-1}\left(q_{1}^{\alpha}+q_{2}^{\alpha}\right)-c_{3} q_{1}^{\alpha-1}\left(q_{2}^{\alpha}+q_{3}^{\alpha}\right)=0, \\
& c_{3} q_{2}^{\alpha-1}\left(q_{1}^{\alpha}+q_{3}^{\alpha}\right)-c_{2} q_{3}^{\alpha-1}\left(q_{1}^{\alpha}+q_{2}^{\alpha}\right)=0 .
\end{aligned}
$$

Solving the algebraic system yields the following steady states:

$$
\begin{aligned}
& e_{1}=\left(q_{1}^{*}, 0,0\right), \\
& e_{2}=\left(0, q_{2}^{*}, 0\right),
\end{aligned}
$$

$$
\begin{aligned}
& e_{3}=\left(0,0, q_{3}^{*}\right), \\
& \text { ne }=\left(q_{1}^{*}, q_{2}^{*}, q_{3}^{*}\right),
\end{aligned}
$$

where $q_{i}^{*} \in \mathbb{R}^{+}$and ne represents Nash equilibrium point. The most important thing here is to study the stability of Nash point. Analytically, stability of Nash requires evaluating the Jacobian matrix at it and calculate its corresponding eigenvalues. Unfortunately, the expression of Nash ne = $\left(q_{1}^{*}, q_{2}^{*}, q_{3}^{*}\right)$ is so complicated and hence nothing can be said. We still have something to say about the complex characteristics through numerical simulation, which is given next for some cases.

Case 1 (no symmetry). Putting $\alpha=0.5$ in (10) yields the following system:

$$
\begin{aligned}
& q_{1, t+1}=q_{1, t}+k_{1}\left(\frac{\sqrt{q_{2}}+\sqrt{q_{3}}}{2 \sqrt{q_{1}}\left(\sqrt{q_{1}}+\sqrt{q_{2}}+\sqrt{q_{3}}\right)^{2}}-c_{1}\right), \\
& q_{2, t+1}=q_{2, t}+k_{2}\left(\frac{\sqrt{q_{1}}+\sqrt{q_{3}}}{2 \sqrt{q_{2}}\left(\sqrt{q_{1}}+\sqrt{q_{2}}+\sqrt{q_{3}}\right)^{2}}-c_{2}\right) \text {, } \\
& q_{3, t+1}=q_{3, t}+k_{3}\left(\frac{\sqrt{q_{1}}+\sqrt{q_{2}}}{2 \sqrt{q_{3}}\left(\sqrt{q_{1}}+\sqrt{q_{2}}+\sqrt{q_{3}}\right)^{2}}-c_{3}\right) .
\end{aligned}
$$

Proposition 1. The Nash equilibrium of system (10) satisfies the condition $\left(\sqrt{q_{1}}-\sqrt{q_{2}}\right) /\left(\sqrt{q_{2}}-\sqrt{q_{3}}\right)=\left(c_{1} \sqrt{q_{1}}-c_{2} \sqrt{q_{2}}\right) /$ $\left(c_{2} \sqrt{q_{2}}-c_{3} \sqrt{q_{3}}\right)$.

Proof. By sitting $q_{i, t+1}=q_{i, t}, i=1,2,3$, in (10), one gets

$$
\begin{gathered}
\frac{\sqrt{q_{2}}+\sqrt{q_{3}}}{2 \sqrt{q_{1}}\left(\sqrt{q_{1}}+\sqrt{q_{2}}+\sqrt{q_{3}}\right)^{2}}-c_{1}=0, \\
\frac{\sqrt{q_{1}}+\sqrt{q_{3}}}{2 \sqrt{q_{2}}\left(\sqrt{q_{1}}+\sqrt{q_{2}}+\sqrt{q_{3}}\right)^{2}}-c_{2}=0, \\
\frac{\sqrt{q_{1}}+\sqrt{q_{2}}}{2 \sqrt{q_{3}}\left(\sqrt{q_{1}}+\sqrt{q_{2}}+\sqrt{q_{3}}\right)^{2}}-c_{3}=0
\end{gathered}
$$

and by simple computations, it is easy to prove that $\left(\sqrt{q_{1}}-\right.$ $\left.\sqrt{q_{2}}\right) /\left(\sqrt{q_{2}}-\sqrt{q_{3}}\right)=\left(c_{1} \sqrt{q_{1}}-c_{2} \sqrt{q_{2}}\right) /\left(c_{2} \sqrt{q_{2}}-c_{3} \sqrt{q_{3}}\right)$. Knowing no explicit form of Nash equilibrium does not give any information about its stability and hence we study its stability numerically by assuming that $c_{1}=0.19, c_{2}=0.18$, and $c_{3}=0.17$. This gives the following Nash point: ne $=$ $(0.5736977767,0.6170010524,0.6653988313)$. The Jacobian at this point takes the form

$$
J=\left[\begin{array}{ccc}
1-0.2719454580 k_{1} & -0.02702099162 k_{1} & -0.02601975598 k_{1} \\
-0.02522346292 k_{2} & 1-0.2430223650 k_{2} & -0.02342099165 k_{2} \\
-0.02242469878 k_{3} & -0.02162346300 k_{3} & 1-0.2161009218 k_{3}
\end{array}\right]
$$




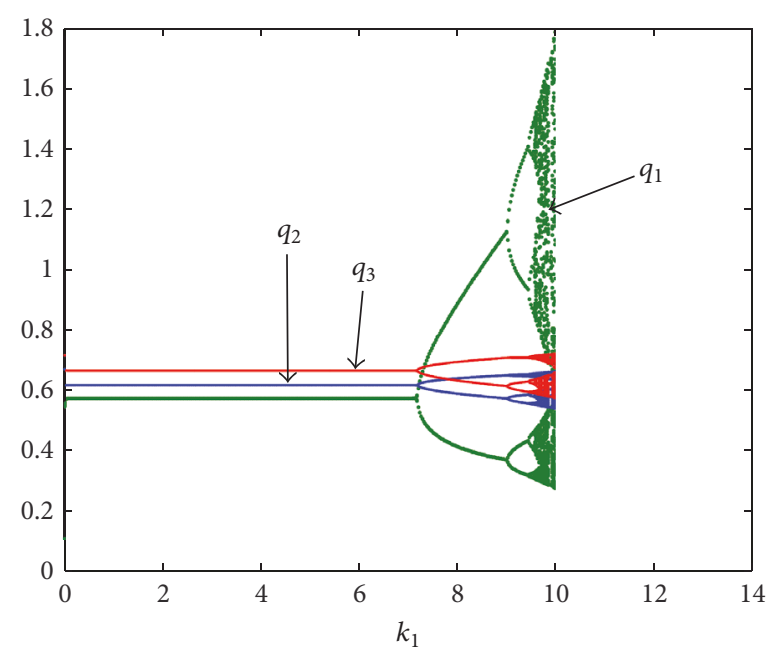

(a)

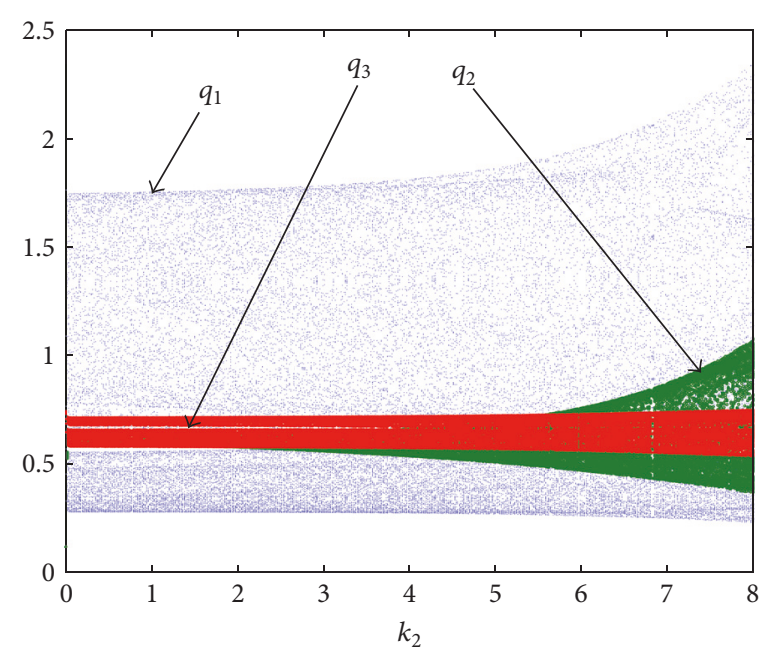

(b)

FIGURE 1: Bifurcation diagram for system (10) with respect to the parameter: (a) $k_{1}$ and the values of the other parameters are fixed, $k_{2}=4$, $k_{3}=5, c_{1}=0.19, c_{2}=0.18$, and $c_{3}=0.17$; (b) $k_{2}$ and the values of the other parameters are fixed, $k_{1}=10, k_{3}=5, c_{1}=0.19, c_{2}=0.18$, and $c_{3}=0.17$.

whose characteristic equation is given by

$$
\vartheta^{3}+A_{1} \vartheta^{2}+A_{2} \vartheta+A_{3}=0
$$

where

$$
\begin{aligned}
A_{1}= & -3+0.2719454580 k_{1}+0.2430223650 k_{2} \\
& +0.2161009218 k_{3}, \\
A_{2}= & 0.06540726537 k_{1} k_{2}+0.05818417896 k_{1} k_{3} \\
& +0.05201091414 k_{1} k_{3}-0.4860447300 k_{2} \\
& -0.4322018436 k_{3}-0.5438909160 k_{1}+3, \\
A_{3}= & -1+0.2719454580 k_{1}+0.2430223650 k_{2} \\
& -0.05201091414 k_{2} k_{3}-0.05818417896 k_{1} k_{3} \\
& -0.06540726537 k_{1} k_{2}+0.2161009218 k_{3} .
\end{aligned}
$$

For ne to be locally asymptotically stable, the following Routh-Hurwitz conditions should be satisfied:

$$
\begin{aligned}
1+A_{1}+A_{2}+A_{3} & >0, \\
1-A_{1}+A_{2}-A_{3} & >0, \\
A_{3}^{2} & <1, \\
\left(1-A_{3}^{2}\right)^{2}-\left(A_{2}-A_{1} A_{3}\right)^{2} & >0 .
\end{aligned}
$$

Now, some numerical simulations are carried out to get more insights into the stability of system (10). Such simulations contain bifurcation diagrams, phase portrait, Lyapunov exponents, basin of attraction, and 2D bifurcation diagram. System (10) includes six parameters, three parameters for the speed of adjustments $k_{1}, k_{2}$, and $k_{3}$ and three parameters for the firms' costs $c_{1}, c_{2}$, and $c_{3}$. Let us first fix the values of $k_{2}$, $k_{3}, c_{1}, c_{2}$, and $c_{3}$ and see the influence of the parameter $k_{1}$ on the system. Let $k_{2}=4, k_{3}=5, c_{1}=0.19, c_{2}=0.18$, and $c_{3}=0.17$. Figure 1 (a) clearly shows a bifurcation diagram that appears when $k_{1}$ becomes close to the value $k_{1}=7.221$. After that a sequence of period doubling bifurcations appeared and this leads to the instability of the equilibrium point. To see the influences of the parameter $k_{2}$ on the system behavior (10), we take $k_{1}=10, k_{3}=5, c_{1}=0.19, c_{2}=0.18$, and $c_{3}=0.17$. Figure $1(\mathrm{~b})$ shows that the behavior of system (10) is entirely unstable. The system is chaotic for any value of the parameter $k_{2}$. It is shown that Nash equilibrium point loses its stability for any values for the speed of adjustment $k_{2}$. Similarly, Figure 2(a) shows that the system's behavior against the parameter $k_{3}$ is entirely unstable. The system contains some other parameters that may have influences on the stability of system behavior. These parameters are the cost parameters. To see the influences of these parameters, let us fix the following: $k_{1}=10, k_{2}=4, k_{3}=5, c_{2}=0.18$, and $c_{3}=0.17$; it is shown in Figure 2(b) that flip bifurcation is detected and therefore the system is unstable against the cost parameter $c_{1}$. The simulation has shown that any value of the cost parameter $c_{1}$ will not give any stabilization of Nash point. Furthermore, as shown in (15), Nash equilibrium depends on those costs' parameter and hence any value for those parameters alters the value of Nash point and gives instability of it. The same results are obtained for the other cost parameters by using $c_{2}$ or $c_{3}$ instead of $c_{1}$. Figures 3(a) and 3(b) show the phase portrait and strange attractor of system (10) at the same set of cost parameters but different values of the speed of adjustment parameters.

Because of the nonlinearity of the system, more complex coexistence characteristics may be detected. For example, 


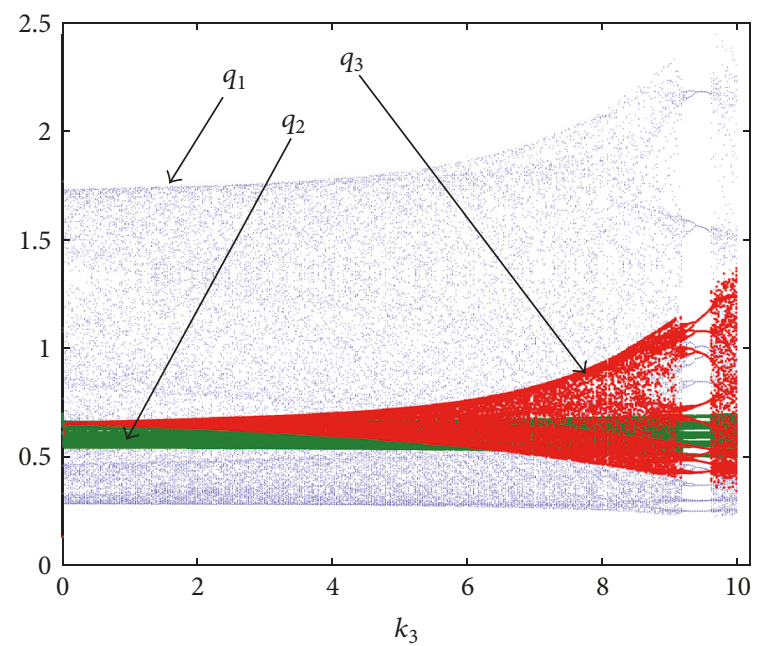

(a)

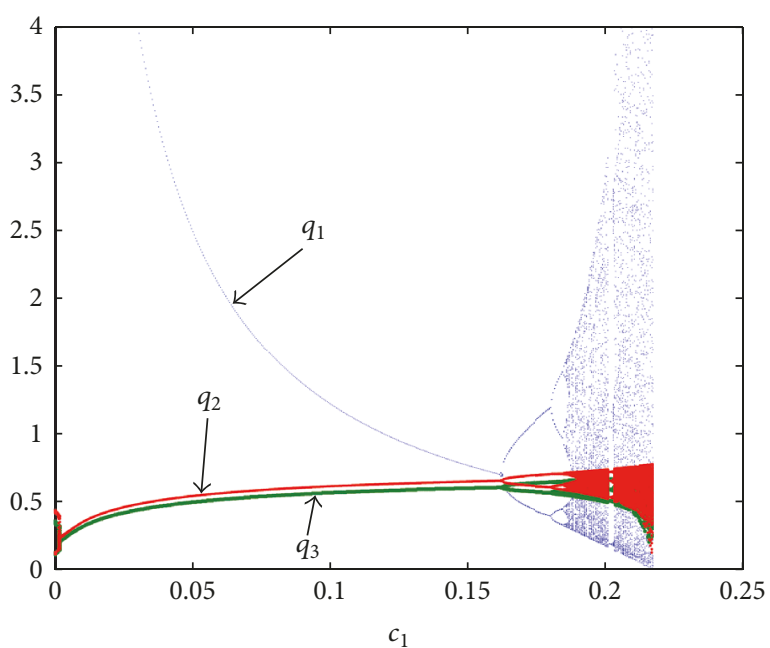

(b)

FIGURE 2: Bifurcation diagram for system (10) with respect to the parameter: (a) $k_{3}$ and the values of the other parameters are fixed, $k_{2}=4$, $k_{3}=5, c_{1}=0.19, c_{2}=0.18$, and $c_{3}=0.17$; (b) $c_{1}$ and the values of the other parameters are fixed, $k_{1}=10, k_{2}=4, k_{3}=5, c_{2}=0.18$, and $c_{3}=0.17$.

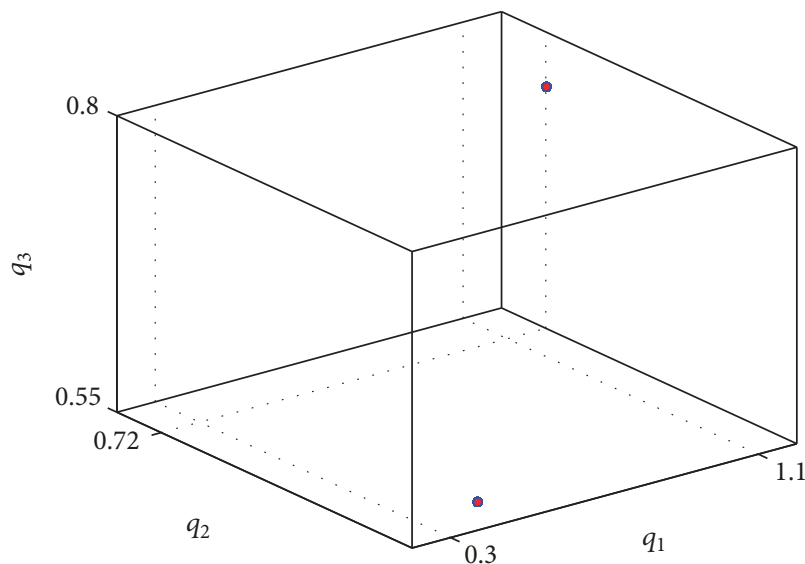

(a)

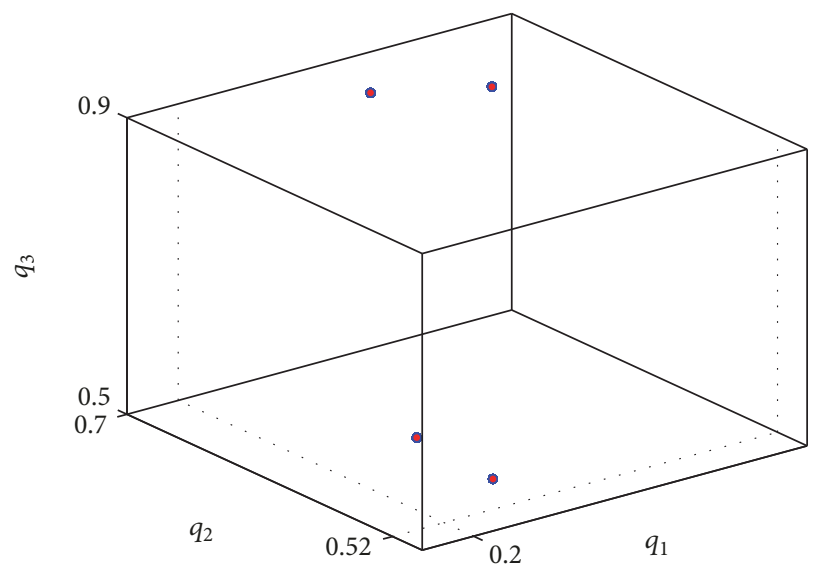

(b)

Figure 3: (a) Phase portrait for 2 cycles at $k_{1}=8.5, k_{2}=5, k_{3}=7, c_{1}=0.19, c_{2}=0.18$, and $c_{3}=0.17$. (b) Phase portrait for 4 cycles at $k_{1}=9$, $k_{2}=5, k_{3}=7.5, c_{1}=0.19, c_{2}=0.18$, and $c_{3}=0.17$.

Figures 3(a), 3(b), and 4(a) show different types of stable period cycles. By taking planar sections of the three dimensional basins, Figure 4(b) shows a section of the basin of attraction of period cycle 2 at $q_{3}=5.04$ which is parallel to the $\left(q_{1}, q_{2}\right)$ coordinate plane. The basin of attraction in Figure 4(b) contains different colors, in which the grey color refers to the basin of attraction of the diverging trajectories and the other two colors are for the basin of attraction of period cycle 2. Similarly, Figures 5(a) and 5(b) show planar sections of the basin of attraction for period cycles 4 and 8 , respectively. These sections are obtained at $q_{3}=5.39$ and $q_{3}=5.81$. In Figure 6, different chaotic attractors for system (10) are given and this makes us study more the influences of the system's parameters on it. In the $\left(k_{1}, k_{2}\right)$-plane, where we fix the other parameters to $q_{0,1}=0.11, q_{0,2}=0.12$, $q_{3,0}=0.13, k_{3}=5, c_{1}=0.19, c_{2}=0.18$, and $c_{3}=0.17$, cycles with different periods are detected and are presented in Figure 7(a). This figure presents a 2D bifurcation diagram of different types of period cycles of system (10). These cycles are of period 1 (basin in grey), period 2 (basin in blue), period 4 (basin in red), period 6 (basin in green), period 8 (basin in yellow), and period 9 (basin in cyan) and the white color is associated with unfeasible trajectories. From the bifurcation diagrams given above, all these cycles become unstable by increasing the values of the parameters $k_{1}, k_{2}$, and $k_{3}$ giving the appearance of cycles with high periodicity and then rise of chaotic attractors. We follow the same procedure of discussion regarding the costs parameters. Figure $7(\mathrm{~b})$ depicts the 2D bifurcation diagram for the cost parameters in the plane $\left(c_{1}, c_{2}\right)$ at $q_{0,1}=0.11, q_{0,2}=0.12, q_{3,0}=0.13$, 


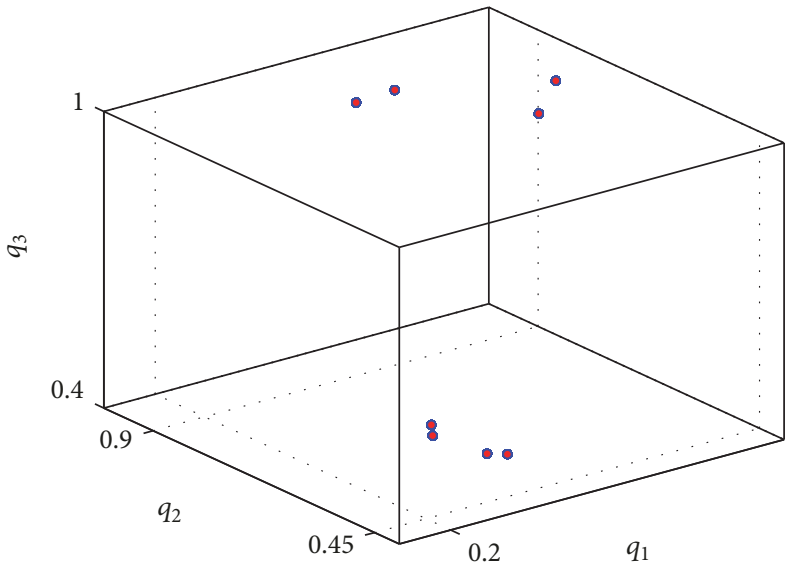

(a)

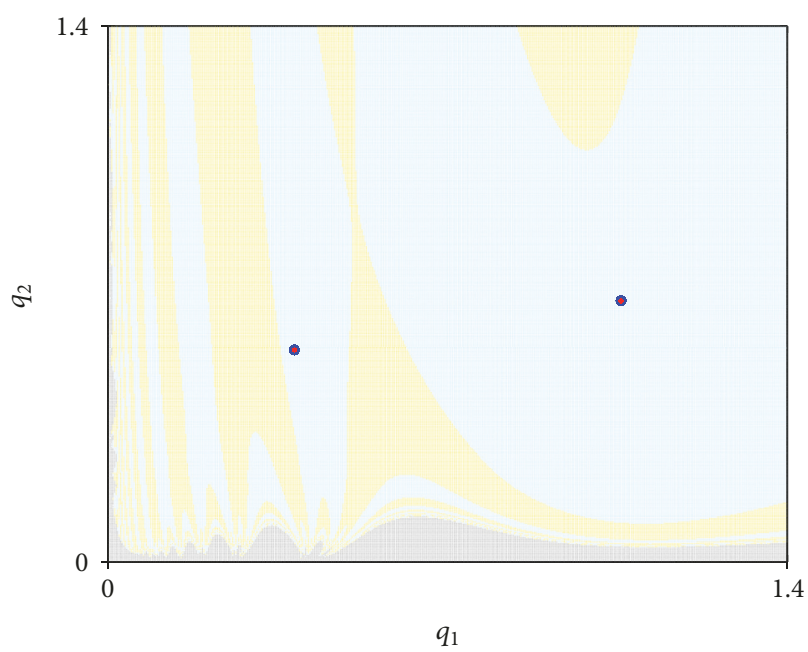

(b)

Figure 4: (a) Phase portrait for 8 cycles at $k_{1}=8.75, k_{2}=7, k_{3}=8.1, c_{1}=0.19, c_{2}=0.18$, and $c_{3}=0.17$. (b) Plane section of basin of attraction at $k_{1}=8.5, k_{2}=5, k_{3}=7, c_{1}=0.19, c_{2}=0.18, c_{3}=0.17$, and $q_{3}=5.04$.

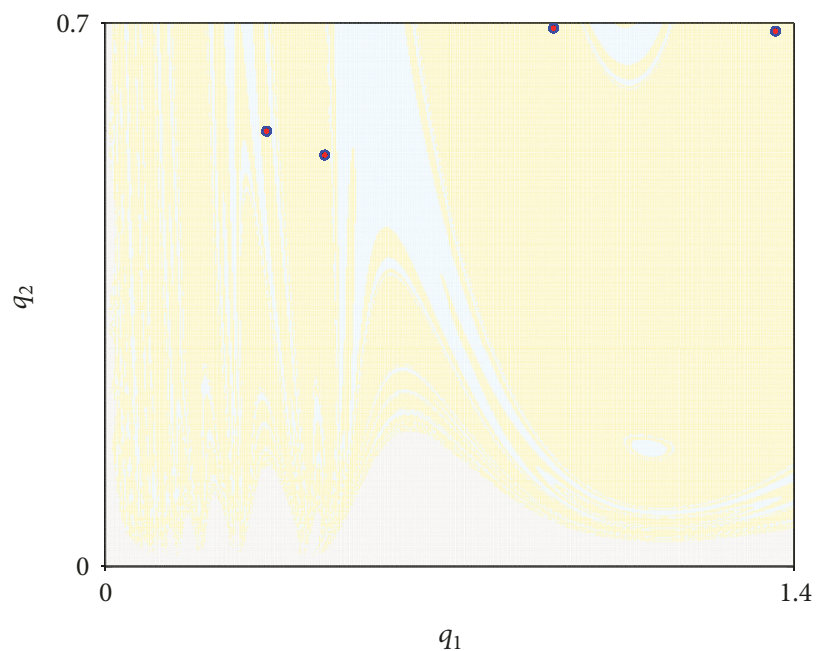

(a)

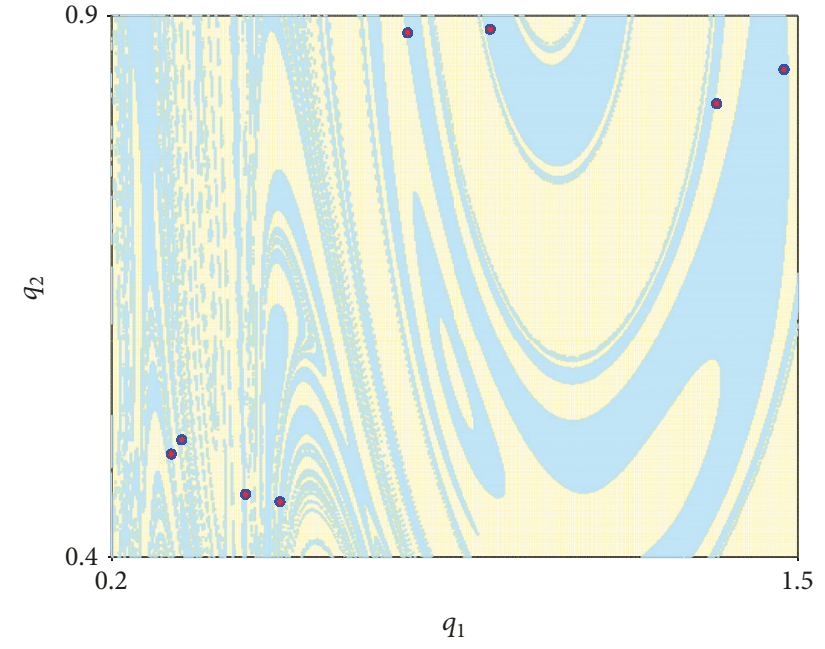

(b)

Figure 5: (a) Plane section of basin of attraction at $k_{1}=9, k_{2}=5, k_{3}=7.5, c_{1}=0.19, c_{2}=0.18, c_{3}=0.17$, and $q_{3}=5.39$. (b) Plane section of basin of attraction at $k_{1}=8.75, k_{2}=7, k_{3}=8.1, c_{1}=0.19, c_{2}=0.18, c_{3}=0.17$, and $q_{3}=5.81$.

$k_{1}=8.5, k_{2}=5, k_{3}=7$, and $c_{3}=0.17$. Different colors refer to different types of periodic cycles.

Case 2 (homogeneous and symmetric case). In this case, we assume a homogeneous and symmetric case by fixing the parameters $k_{1}=k_{2}=k_{3}=k$ and $c_{1}=c_{2}=c_{3}=c$. Putting $c=0.2$ in (15) gives the following Nash equilibrium: ne $=(0.56,0.56,0.56)$. Figure 8 (a) shows a flip bifurcation in which the Nash point is asymptotically stable for values of the $k$ parameters less than 5.53 but for any values for the cost parameter $c$ in $(0,0.2)$ the point becomes entirely unstable, as given in Figure 8(b). Another useful tool of numerical simulation is to study the maximum Lyapunov exponents (MLE) as function of interested system's parameters. It is clear in Figures 8(c) and 8(d) that the value of MLE changes from negative to positive at the bifurcation point and hence the system equilibrium point becomes unstable.

In Figure 9(a), we present the basin of attraction regarding the two parameters $k$ and $c$. The figure shows a number of cycles with different periods. The white color in it refers to the unfeasible trajectories, while the grey one presents the diverging trajectories. The other figure gives the phase portrait of the behavior of the studied system (Figure 9(b)). Now, we give some brief studied cases for the system at different values of the parameter $\alpha$. We start with $\alpha=0.3$ (interchangeable commodities but not quite identical) with the same set of cost parameters. It is shown in Figure 10(a) that the Nash point in this case loses its stability due to bifurcation. We observe, however, that there is an asymptotic stability of 


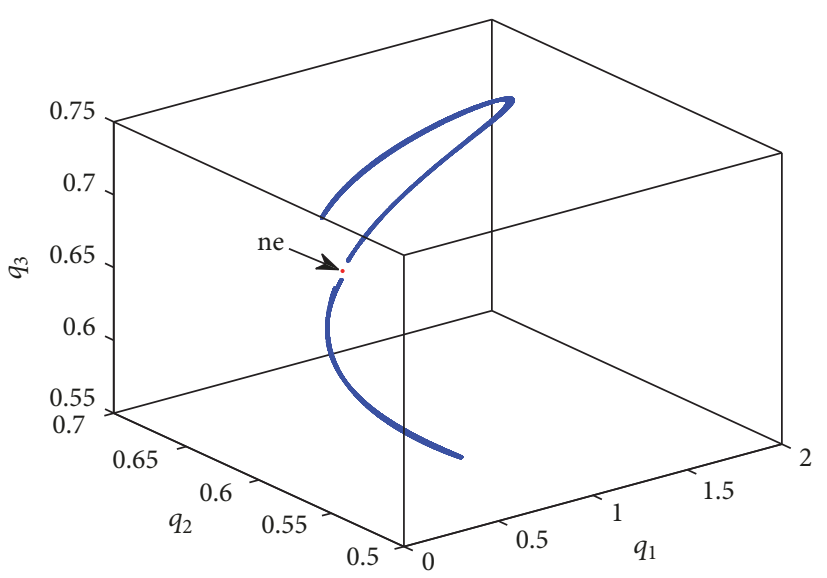

(a)

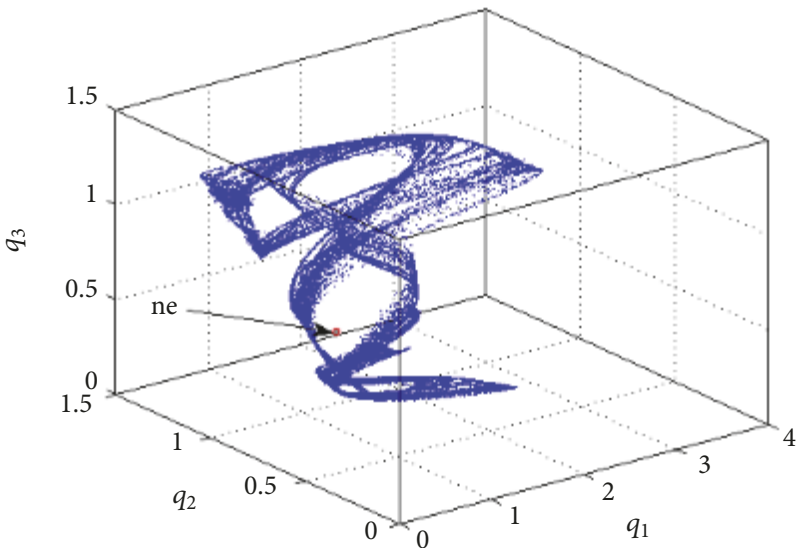

(b)

FIGURE 6: Phase portrait at (a) $k_{1}=10, k_{2}=4, k_{3}=5, c_{1}=0.19, c_{2}=0.18, c_{3}=0.17$ (b) $k_{1}=10, k_{2}=8, k_{3}=9, c_{1}=0.19, c_{2}=0.18$, and $c_{3}=0.17$.

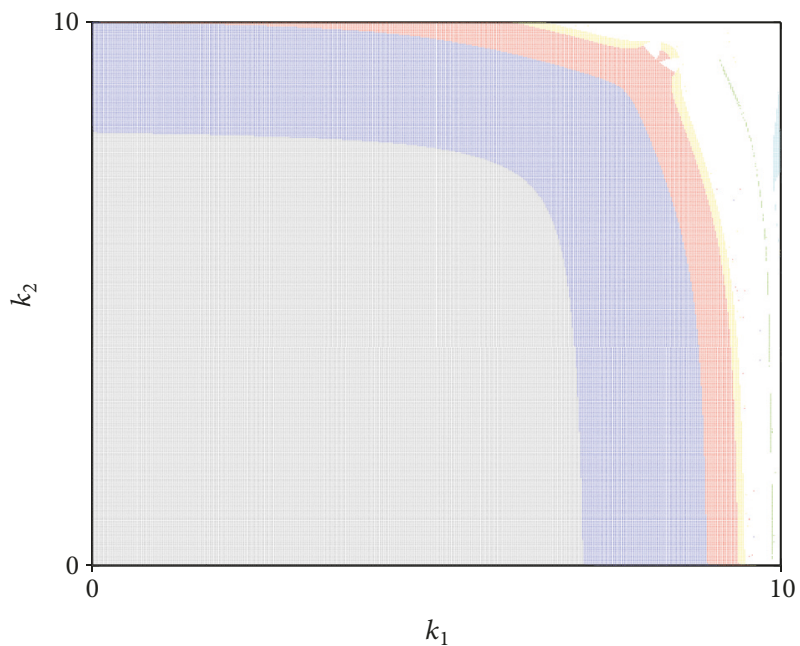

(a)

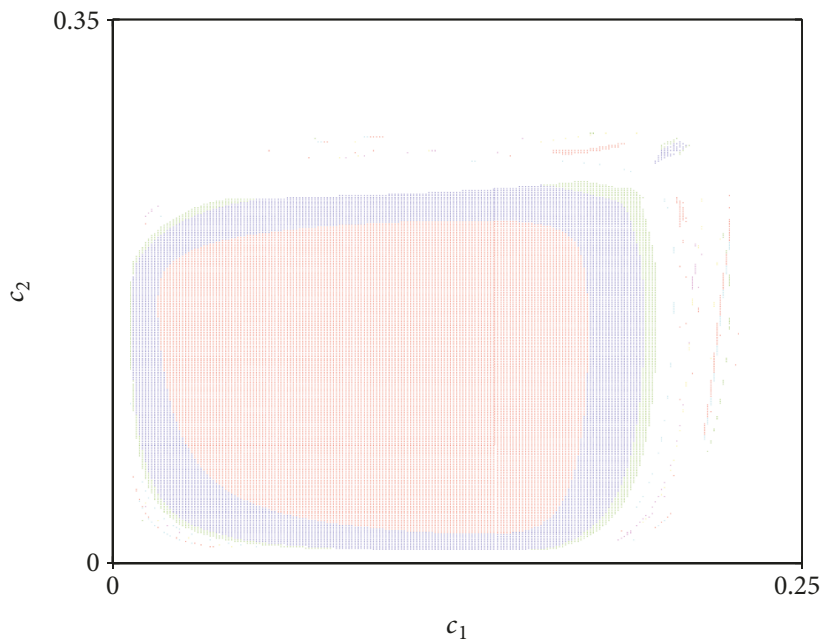

(b)

Figure 7: (a) 2D bifurcation diagram in the plane $\left(k_{1}, k_{2}\right)$ at $q_{0,1}=0.11, q_{0,2}=0.12, q_{3,0}=0.13, k_{3}=7, c_{1}=0.19, c_{2}=0.18$, and $c_{3}=0.17$. (b) $2 \mathrm{D}$ bifurcation diagram in the plane $\left(c_{1}, c_{2}\right)$ at $q_{0,1}=0.11, q_{0,2}=0.12, q_{3,0}=0.13, k_{1}=8.5, k_{2}=5, k_{3}=7$, and $c_{3}=0.17$.

Nash point in this case. Some other useful numerical tools to inspect the influence of the system's parameters on the trajectories, whether they converge to periodic orbits and chaotic attractor, are discussed. The maximum Lyapunov exponent (MLE) gives an evident for the occurrence of chaos when it takes positive values. In order to get a better view for MLE, the dynamic system is left to evolve for $t=10^{4}$ time units and then the Lyapunov exponent is calculated according to that value. It is clear in Figure 10(b) that for both parameters $c_{1}$ and $k_{1}$ is positive and consequently existence of chaotic motions is appeared. Finally, Figures 10 (c) and 10(d) show the phase portrait and the bifurcation diagram for the system at $\alpha=0.3$. It is clear that the system is unstable for any values for the cost parameter $c_{1}$. Another interesting case is when $\alpha=0.7$. This case gives a more complicated behavior of the system. Figure 11(a) shows the bifurcation diagram and as one can see Nash point is unstable. In addition, coexistence of four-piece chaotic attractor is detected and plotted in Figure 11(b) at $k_{1}=12, k_{2}=12, k_{3}=14, c_{1}=0.19, c_{2}=0.18$, and $c_{3}=0.17$.

\section{Conclusion}

In this paper, a utility function that is derived from the CES production function has been used to study the competition among three Cournot firms. Analysis of this competition has been performed under the assumption of linear cost function and for some important cases on which substitutability degree among commodities has been considered. Numerical simulations have been used to confirm either the stability or the instability of Nash equilibrium point. The numerical results have shown that the stability of the 


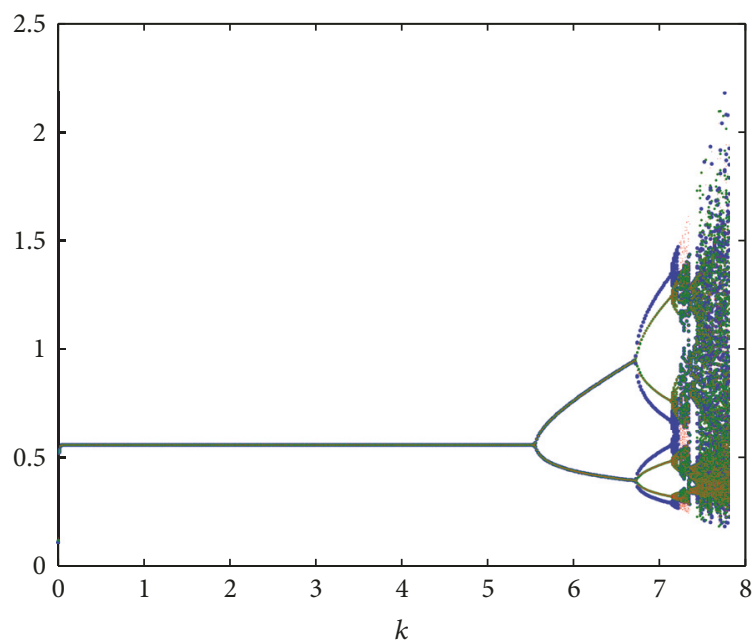

- $q_{1}$ (blue)

- $q_{2}$ (green)

$q_{3}($ red $)$

(a)

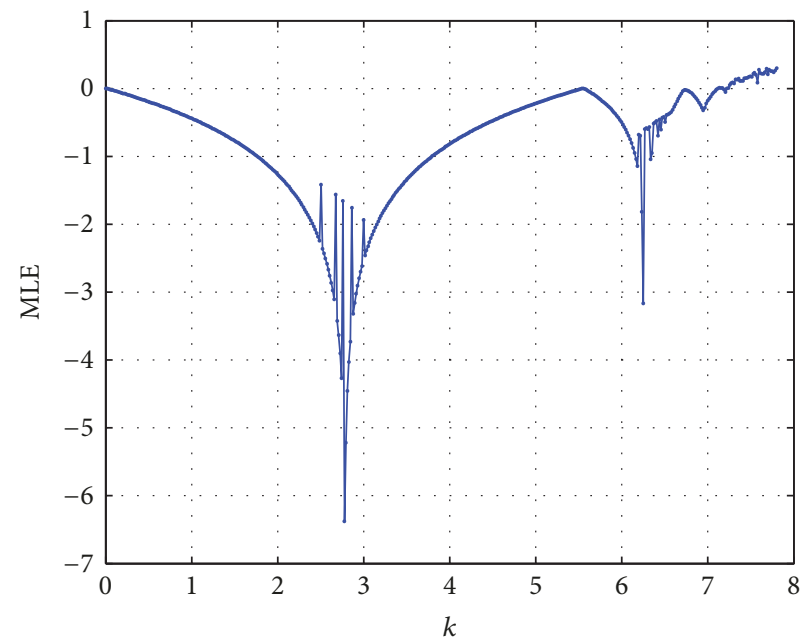

(c)

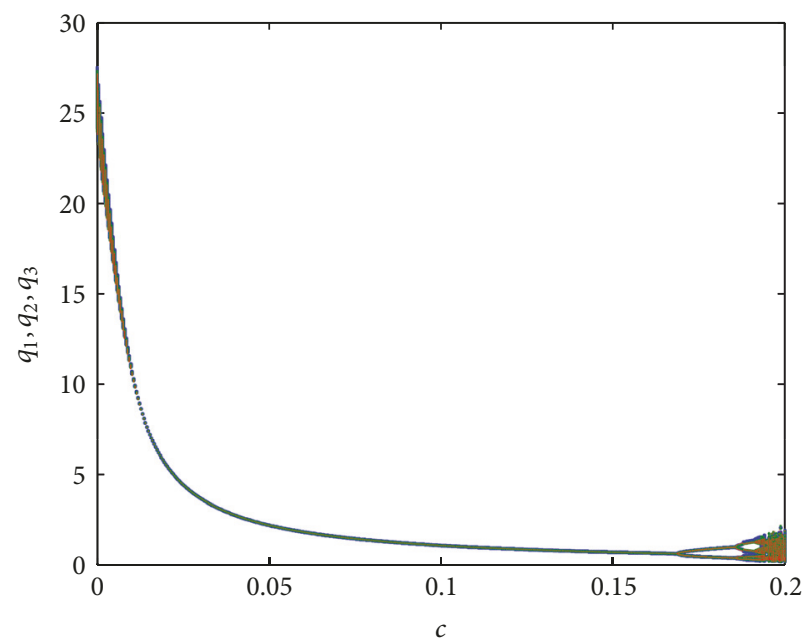

(b)

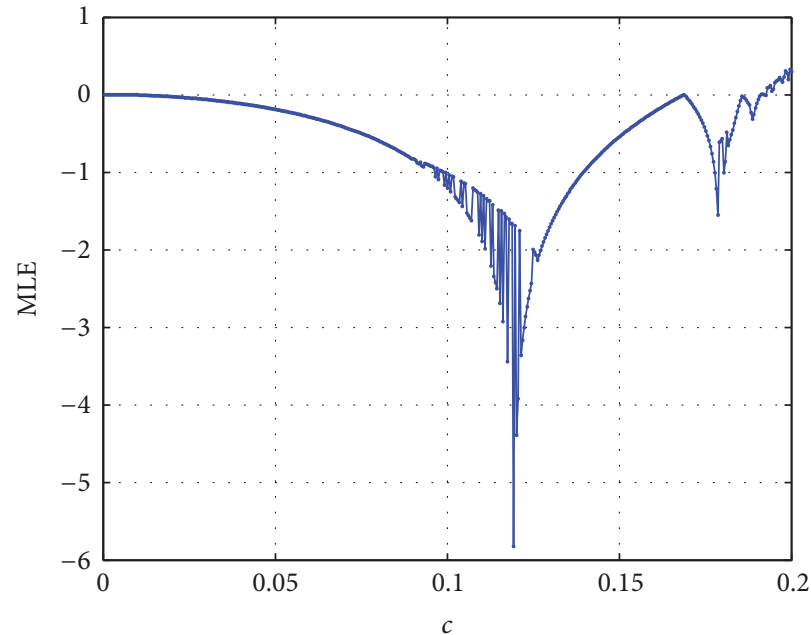

(d)

FiguRe 8: (a) Bifurcation diagram for the symmetric case of system (10) at $c=0.2, q_{0,1}=0.11, q_{0,2}=0.12$, and $q_{3,0}=0.13$. (b) Bifurcation diagram for the symmetric case of system (10) at $k=7.8, q_{0,1}=0.11, q_{0,2}=0.12$, and $q_{3,0}=0.13$. (c) The maximum Lyapunov exponents with respect to $k$. (d) The maximum Lyapunov exponents with respect to $c$.

equilibrium point has been affected by bifurcation routed to chaos. Furthermore, the obtained results have confirmed the bad influences of parameters on the behavior of the system. The results obtained in this paper have extended existing results in literature that have studied duopoly cases.

\section{Appendix}

Using the utility function and the budget constraint, the Lagrange function is written as follows:

$$
\begin{aligned}
\mathscr{L}\left(q_{1}, q_{2}, q_{3}, \lambda\right)= & q_{1}^{\alpha}+q_{2}^{\alpha}+q_{3}^{\alpha} \\
& +\lambda\left(1-p_{1} q_{1}-p_{2} q_{2}-p_{3} q_{3}\right),
\end{aligned}
$$

where $\lambda$ is defined as a Lagrange multiplier. The first-order conditions of (A.1) yield

$$
\begin{aligned}
& \frac{\partial \mathscr{L}}{\partial q_{1}}=\alpha q_{1}^{\alpha-1}-\lambda p_{1}=0, \\
& \frac{\partial \mathscr{L}}{\partial q_{2}}=\alpha q_{2}^{\alpha-1}-\lambda p_{2}=0, \\
& \frac{\partial \mathscr{L}}{\partial q_{3}}=\alpha q_{3}^{\alpha-1}-\lambda p_{3}=0, \\
& \frac{\partial \mathscr{L}}{\partial \lambda}=1-p_{1} q_{1}-p_{2} q_{2}-p_{3} q_{3}=0
\end{aligned}
$$




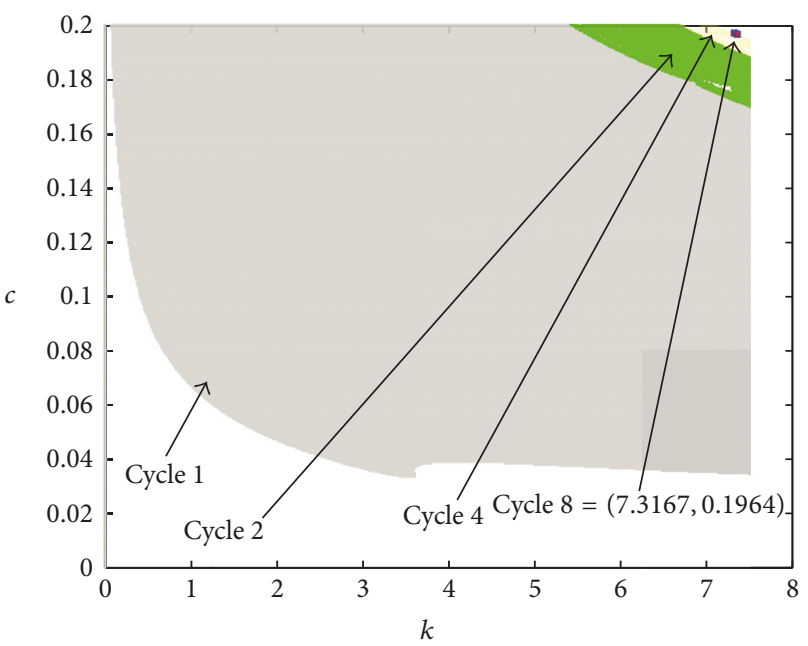

(a)

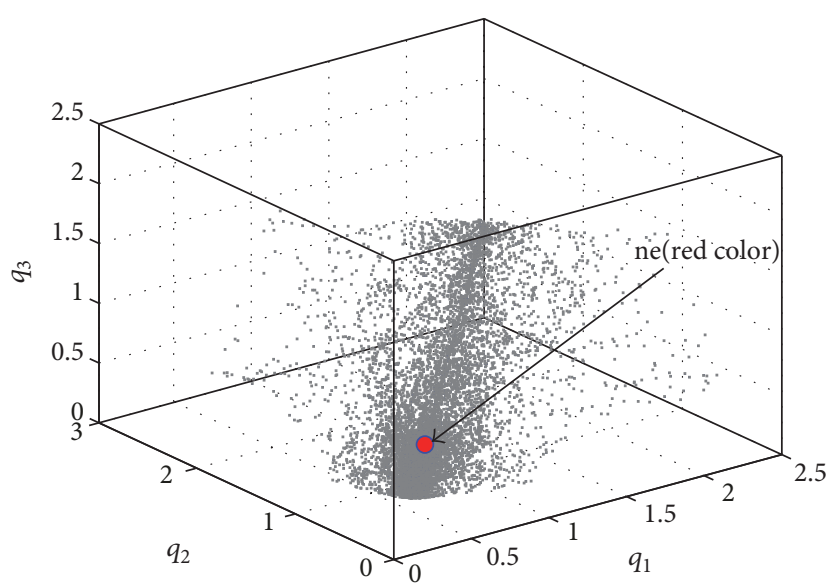

(b)

Figure 9: (a) 2D bifurcation diagram of $k$ versus $c$ at $q_{0,1}=0.11, q_{0,2}=0.12$, and $q_{3,0}=0.13$. (b) Phase portrait at $k=7.8, c=0.2, q_{0,1}=0.11$, $q_{0,2}=0.12$, and $q_{3,0}=0.13$.

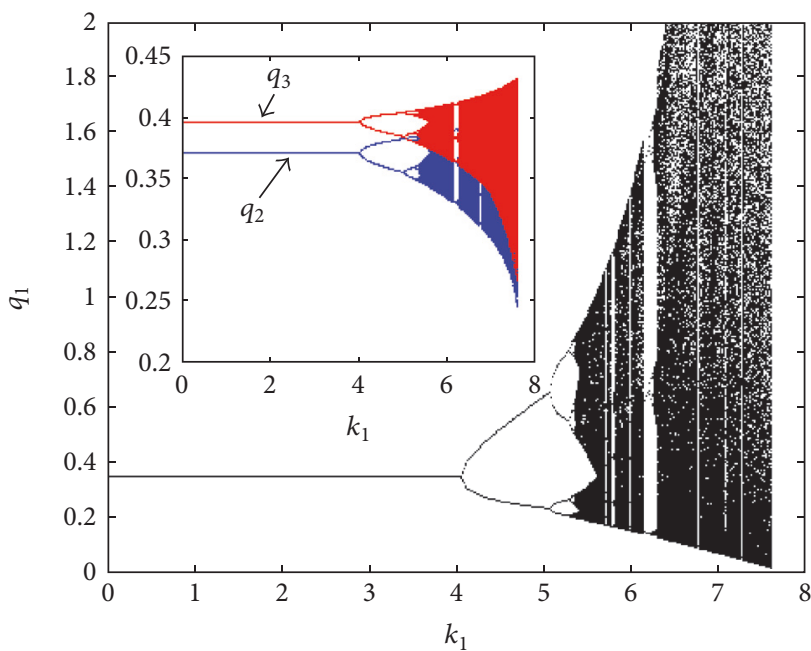

(a)

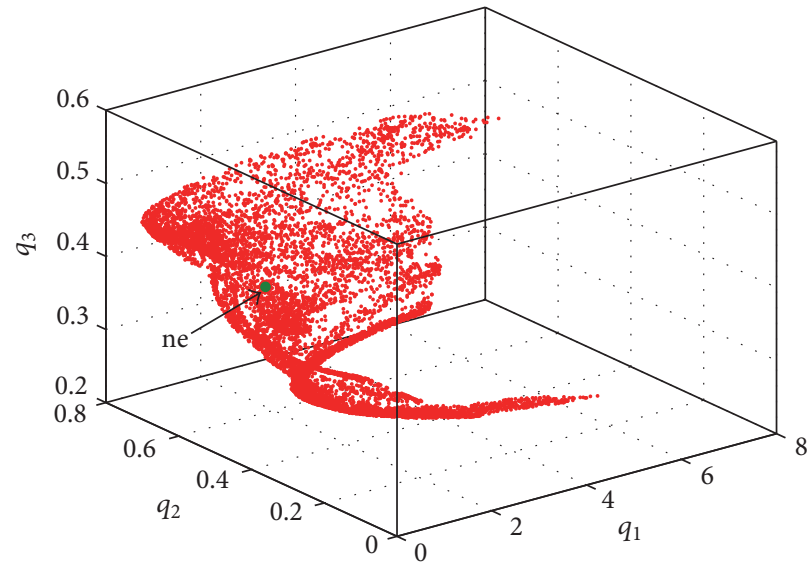

(c)

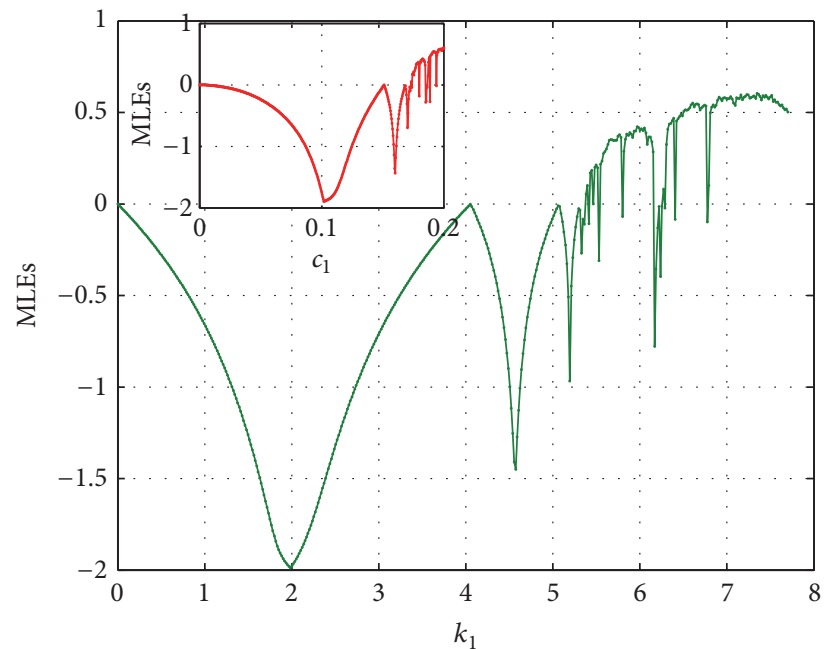

(b)

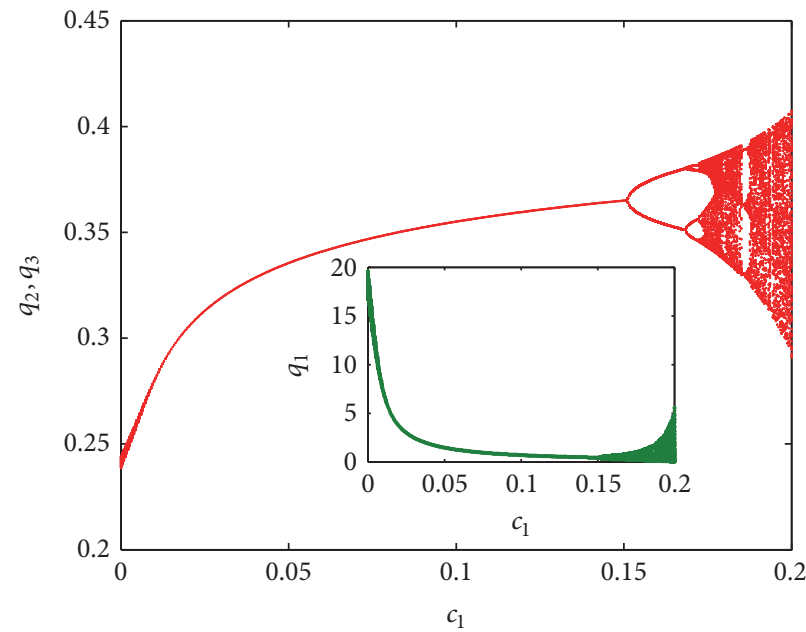

(d)

Figure 10: (a) Bifurcation diagram for the case $(\alpha=0.3)$ with respect to $k_{1}$ at $c_{1}=0.19, c_{2}=0.18, c_{3}=0.17, q_{0,1}=0.11, q_{0,2}=0.12$, and $q_{3,0}=0.13$. (b) The maximum Lyapunov exponents with respect to $k_{1}, c_{1}$. (c) The phase portrait at $k_{1}=6.5, k_{2}=2.5, k_{3}=2.3, c_{1}=0.19$, $c_{2}=0.18$, and $c_{3}=0.17$. (d) Bifurcation diagram for the case $(\alpha=0.3)$ with respect to $c_{1}$ at $k_{1}=6.5, k_{2}=2.5, k_{3}=2.3, q_{0,1}=0.11, q_{0,2}=0.12$, and $q_{3,0}=0.13$. 


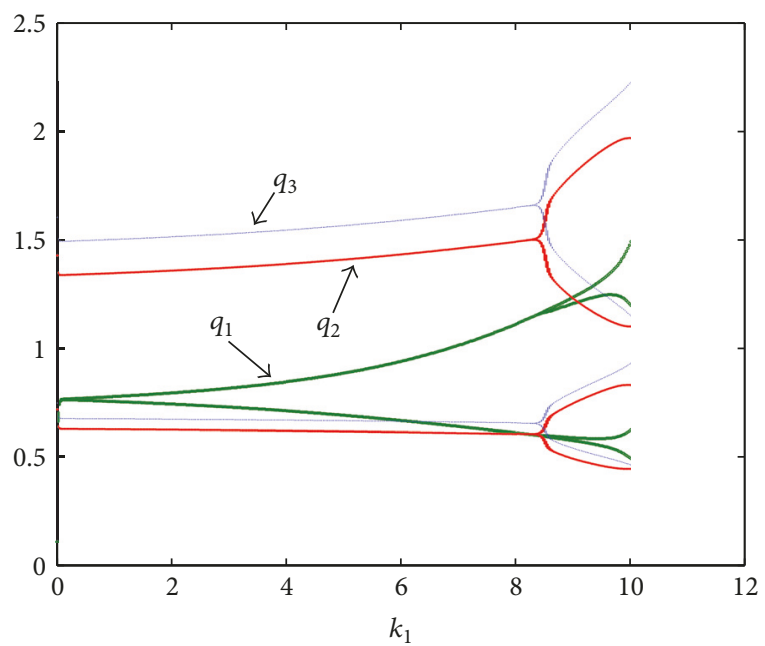

(a)

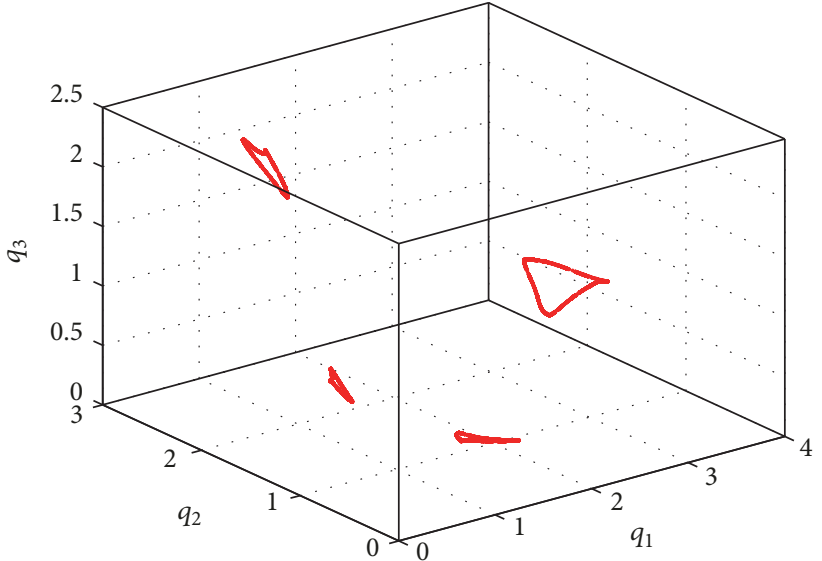

(b)

Figure 11: (a) Bifurcation diagram for the case $(\alpha=0.7)$ with respect to $k_{1}$ at $c_{1}=0.19, c_{2}=0.18, c_{3}=0.17, q_{0,1}=0.11, q_{0,2}=0.12$, and $q_{3,0}=0.13$. (b) The phase portrait at $k_{1}=12, k_{2}=12, k_{3}=14, c_{1}=0.19, c_{2}=0.18$, and $c_{3}=0.17$.

whose solutions are

$$
\begin{aligned}
& p_{1}=\frac{\alpha q_{1}^{\alpha-1}}{\lambda}, \\
& p_{2}=\frac{\alpha q_{2}^{\alpha-1}}{\lambda}, \\
& p_{3}=\frac{\alpha q_{3}^{\alpha-1}}{\lambda} .
\end{aligned}
$$

Using the budget constraints with simple calculations, one can easily get

$$
\begin{aligned}
& p_{1}=\frac{q_{1}^{\alpha-1}}{q_{1}^{\alpha}+q_{2}^{\alpha}+q_{3}^{\alpha}}, \\
& p_{2}=\frac{q_{2}^{\alpha-1}}{q_{1}^{\alpha}+q_{2}^{\alpha}+q_{3}^{\alpha}}, \\
& p_{3}=\frac{q_{3}^{\alpha-1}}{q_{1}^{\alpha}+q_{2}^{\alpha}+q_{3}^{\alpha}},
\end{aligned}
$$

which can be rewritten in the form

$$
p_{j}=\frac{q_{j}^{\alpha-1}}{\sum_{i=1}^{3} q_{i}^{\alpha}} \text {. }
$$

\section{Conflicts of Interest}

The authors declare that there are no conflicts of interest regarding the publication of this paper.

\section{Acknowledgments}

The authors would like to extend their sincere appreciation to the Deanship of Scientific Research at King Saud University for funding this research (Group no. RG-1435-054).

\section{References}

[1] L. Sun and J. Ma, "Study and simulation on discrete dynamics of Bertrand Triopoly team-game," Mathematical Problems in Engineering, vol. 2015, Article ID 960380, 12 pages, 2015.

[2] H. Wang and J. Ma, "Complexity analysis of a cournotbertrand duopoly game model with limited information," Discrete Dynamics in Nature and Society, vol. 2013, Article ID 287371, 6 pages, 2013.

[3] H. N. Agiza and A. A. Elsadany, "Nonlinear dynamics in the Cournot duopoly game with heterogeneous players," Physica A: Statistical Mechanics and Its Applications, vol. 320, no. 1-4, pp. 512-524, 2003.

[4] A. Cournot, Researches into the Principles of the Theory of Wealth, Researches into the Principles of the Theory of Wealth, Hachette, Paris, France, 1963.

[5] A. A. Elsadany, "A dynamic Cournot duopoly model with different strategies," Journal of the Egyptian Mathematical Society, vol. 23, no. 1, pp. 56-61, 2015.

[6] T. Puu, "The chaotic duopolists revisited," Journal of Economic Behavior \& Organization, vol. 33, no. 3-4, pp. 385-394, 1998.

[7] A. E. Matouk, A. A. Elsadany, and B. Xin, "Neimark-Sacker bifurcation analysis and complex nonlinear dynamics in a heterogeneous quadropoly game with an isoelastic demand function," Nonlinear Dynamics, vol. 89, no. 4, pp. 2533-2552, 2017.

[8] H. N. Agiza, G. I. Bischi, and M. Kopel, "Multistability in a dynamic Cournot game with three oligopolists," Mathematics and Computers in Simulation, vol. 51, no. 1-2, pp. 63-90, 1999.

[9] A. A. Elsadany and A. M. Awad, "Dynamical analysis and chaos control in a heterogeneous Kopel duopoly game," Indian Journal of Pure and Applied Mathematics, vol. 47, no. 4, pp. 617-639, 2016.

[10] S. S. Askar, "On Cournot-Bertrand competition with differentiated products," Annals of Operations Research, vol. 223, pp. 8193, 2014.

[11] G. I. Bischi, C. Mammana, and L. Gardini, "Multistability and cyclic attractors in duopoly games," Chaos, Solitons \& Fractals, vol. 11, no. 4, pp. 543-564, 2000. 
[12] H. N. Agiza and A. A. Elsadany, "Chaotic dynamics in nonlinear duopoly game with heterogeneous players," Applied Mathematics and Computation, vol. 149, no. 3, pp. 843-860, 2004.

[13] J. X. Zhang, Q. L. Da, and Y. H. Wang, "Analysis of nonlinear duopoly game with heterogeneous players," Economic Modelling, vol. 24, no. 1, pp. 138-148, 2007.

[14] A. Matsumoto and Y. Nonaka, "Statistical dynamics in a chaotic Cournot model with complementary goods," Journal of Economic Behavior \& Organization, vol. 61, no. 4, pp. 769-783, 2006.

[15] M. T. Yassen and H. N. Agiza, "Analysis of a duopoly game with delayed bounded rationality," Applied Mathematics and Computation, vol. 138, no. 2-3, pp. 387-402, 2003.

[16] S. S. Askar and M. F. Elettreby, "The impact of cost uncertainty on Cournot oligopoly games," Applied Mathematics and Computation, vol. 312, pp. 169-176, 2017.

[17] K. Alnowibet, S. S. Askar, and A. A. Elsadany, "Complex dynamics and control investigation of a Cournot triopoly game formed based on a log-concave demand function," Advances in Mechanical Engineering, vol. 9, no. 7, pp. 1-8, 2017.

[18] G. I. Bischi and M. Kopel, "Equilibrium selection in a nonlinear duopoly game with adaptive expectations," Journal of Economic Behavior \& Organization, vol. 46, no. 1, pp. 73-100, 2001.

[19] S. S. Askar, "On complex dynamics of monopoly market," Economic Modelling, vol. 31, no. 1, pp. 586-589, 2013.

[20] S. S. Askar, "The rise of complex phenomena in Cournot duopoly games due to demand functions without inflection points," Communications in Nonlinear Science and Numerical Simulation, vol. 19, no. 6, pp. 1918-1925, 2014.

[21] S. S. Askar and A. Al-khedhairi, "Analysis of nonlinear duopoly games with product differentiation: stability, global dynamics, and control," Discrete Dynamics in Nature and Society, vol. 2017, Article ID 2585708, 13 pages, 2017.

[22] T. Puu, "Complex dynamics with three oligopolists," Chaos, Solitons \& Fractals, vol. 7, no. 12, pp. 2075-2081, 1996.

[23] M. F. El-Wakeel, S. S. Askar, and N. A. Alkhunayfir, "Toward investigation of the complex behavior of a monopoly game," Journal of Computational and Theoretical Nanoscience, vol. 13, no. 11, pp. 8552-8559, 2016.

[24] S. S. Askar, A. M. Alshamrani, and K. Alnowibet, "The arising of cooperation in Cournot duopoly games," Applied Mathematics and Computation, vol. 273, pp. 535-542, 2016.

[25] E. M. Elabbasy, H. N. Agiza, A. A. Elsadany, and H. ELMetwally, "The dynamics of triopoly game with heterogeneous players," Journal of Nonlinear Science, vol. 3, pp. 83-90, 2007.

[26] T. Puu, "Chaos in duopoly pricing," Chaos, Solitons \& Fractals, vol. 1, no. 6, pp. 573-581, 1991.

[27] J. Andaluz, A. A. Elsadany, and G. Jarne, "Nonlinear Cournot and Bertrand-type dynamic triopoly with differentiated products and heterogeneous expectations," Mathematics and Computers in Simulation, vol. 132, pp. 86-99, 2017.

[28] H. Tu and X. Wang, "Research on a Dynamic master-slave Cournot triopoly game model with bounded rational rule and its control," Mathematical Problems in Engineering, vol. 2016, Article ID 2353909, 11 pages, 2016.

[29] J.-H. Ma and W.-Z. Ji, "Complexity of repeated game model in electric power triopoly," Chaos, Solitons \& Fractals, vol. 40, no. 4, pp. 1735-1740, 2009.

[30] W. Ji, "Chaos and control of game model based on heterogeneous expectations in electric power triopoly," Discrete Dynamics in Nature and Society, vol. 2009, Article ID 469564, 8 pages, 2009.
[31] E. M. Elabbasy, H. N. Agiza, and A. A. Elsadany, "Analysis of nonlinear triopoly game with heterogeneous players," Computers and Mathematics with Applications, vol. 57, no. 3, pp. 488499, 2009.

[32] S. S. Askar and A. Alshamrani, "The dynamics of economic games based on product differentiation," Journal of Computational and Applied Mathematics, vol. 268, pp. 135-144, 2014.

[33] S. Brianzoni, L. Gori, and E. Michetti, "Dynamics of a Bertrand duopoly with differentiated products and nonlinear costs: analysis, comparisons and new evidences," Chaos, Solitons \& Fractals, vol. 79, pp. 191-203, 2015.

[34] L. Zhao and J. Zhang, "Analysis of a duopoly game with heterogeneous players participating in carbon emission trading," Nonlinear Analysis: Modelling and Control, vol. 19, no. 1, pp. 118131, 2014.

[35] L. Fanti, L. Gori, C. Mammana, and E. Michetti, "The dynamics of a Bertrand duopoly with differentiated products: Synchronization, intermittency and global dynamics," Chaos, Solitons \& Fractals, vol. 52, no. 1, pp. 73-86, 2013.

[36] J. Zhang, Q. Da, and Y. Wang, "The dynamics of Bertrand model with bounded rationality," Chaos, Solitons \& Fractals, vol. 39, no. 5, pp. 2048-2055, 2009.

[37] J. Peng, The complexity of price game model in oligopoly market and its application [Ph.D. thesis], Tianjin University, Tianjin, China, 2010.

[38] J. Peng, Z. H. Miao, and F. Peng, "Study on a 3-dimensional game model with delayed bounded rationality," Applied Mathematics and Computation, vol. 218, no. 5, pp. 1568-1576, 2011.

[39] J. Zhang and G. Wang, "Complex dynamics of Bertrand duopoly games with bounded rationality," World Academy of Science, Engineering and Technology, vol. 79, pp. 106-110, 2013.

[40] L. U. Yali, "Dynamics of a delayed Duopoly game with increasing marginal costs and bounded rationality strategy," Procedia Engineering, vol. 15, pp. 4392-4396, 2011.

[41] Z. Sun and J. Ma, "Complexity of triopoly price game in Chinese cold rolled steel market," Nonlinear Dynamics, vol. 67, no. 3, pp. 2001-2008, 2012.

[42] J. H. Ma and K. F. Wu, "Complex system and influence of delayed decision on the stability of a triopoly price game model," Nonlinear Dynamics, vol. 73, no. 3, pp. 1741-1751, 2013.

[43] A. Arya, B. Mittendorf, and D. E. M. Sappington, "Outsourcing, vertical integration, and price vs. quantity competition," International Journal of Industrial Organization, vol. 26, no. 1, pp. 116, 2008.

[44] J. Hackner, "A note on price and quantity competition in differentiated oligopolies," Journal of Economic Theory, vol. 93, no. 2, pp. 233-239, 2000.

[45] V. Tremblay, C. Tremblay, and K. Isariyawongse, "Endogenous timing and strategic choice: the Cournot-Bertrand model," Working Paper, Oregon State University, 2009.

[46] P. Zanchettin, "Differentiated duopoly with asymmetric costs," Journal of Economics \& Management Strategy, vol. 15, no. 4, pp. 999-1015, 2006.

[47] C. H. Tremblay and V. J. Tremblay, "The Cournot-Bertrand model and the degree of product differentiation," Economics Letters, vol. 111, no. 3, pp. 233-235, 2011.

[48] A. K. Naimzada and F. Tramontana, "Dynamic properties of a Cournot-Bertrand duopoly game with differentiated products," Economic Modelling, vol. 29, no. 4, pp. 1436-1439, 2012.

[49] B. Xin and T. Chen, "On a master-slave Bertrand game model," Economic Modelling, vol. 28, no. 4, pp. 1864-1870, 2011. 
[50] H. Tu, J. Ma, and L. Sun, "Research on a Cournot-Bertrand triopoly game between the upstream firms and the downstream firm," WSEAS Transactions on Systems and Control, vol. 11, pp. 255-265, 2016.

[51] S. Wan, Q. Liu, J. Zou, and W. He, "Nonlinearity and fractal properties of climate change during the past 500 years in northwestern China," Discrete Dynamics in Nature and Society, vol. 2016, Article ID 4269431, 7 pages, 2016.

[52] G. Q. Sun, S. L. Wang, Q. Ren, Z. Jin, and Y. P. Wu, "Effects of time delay and space on herbivore dynamics: linking inducible defenses of plants to herbivore outbreak," Scientific Reports, vol. 5, article 11246, 2015

[53] L. Li, Z. Jin, and J. Li, "Periodic solutions in a herbivoreplant system with time delay and spatial diffusion," Applied Mathematical Modelling, vol. 40, no. 7-8, pp. 4765-4777, 2016.

[54] G.-Q. Sun, "Mathematical modeling of population dynamics with Allee effect," Nonlinear Dynamics, vol. 85, no. 1, pp. 1-12, 2016.

[55] G.-Q. Sun, A. Chakraborty, Q.-X. Liu, Z. Jin, K. E. Anderson, and B.-L. Li, "Influence of time delay and nonlinear diffusion on herbivore outbreak," Communications in Nonlinear Science and Numerical Simulation, vol. 19, no. 5, pp. 1507-1518, 2014.

[56] L. Li and Z. Jin, "Pattern dynamics of a spatial predator-prey model with noise," Nonlinear Dynamics, vol. 67, no. 3, pp. 17371744, 2012.

[57] G.-Q. Sun, J. Zhang, L.-P. Song, Z. Jin, and B.-L. Li, "Pattern formation of a spatial predator-prey system," Applied Mathematics and Computation, vol. 218, no. 22, pp. 11151-11162, 2012.

[58] L. Li, "Patch invasion in a spatial epidemic model," Applied Mathematics and Computation, vol. 258, pp. 342-349, 2015.

[59] G.-Q. Sun, "Pattern formation of an epidemic model with diffusion," Nonlinear Dynamics, vol. 69, no. 3, pp. 1097-1104, 2012.

[60] A. Agliari, A. K. Naimzada, and N. Pecora, "Nonlinear dynamics of a Cournot duopoly game with differentiated products," Applied Mathematics and Computation, vol. 281, pp. 1-15, 2016. 


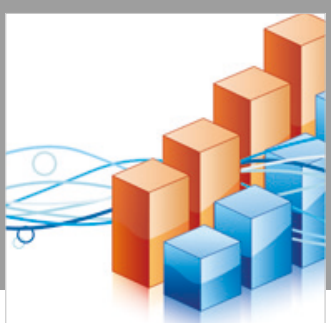

Advances in

Operations Research

\section{-n-m}
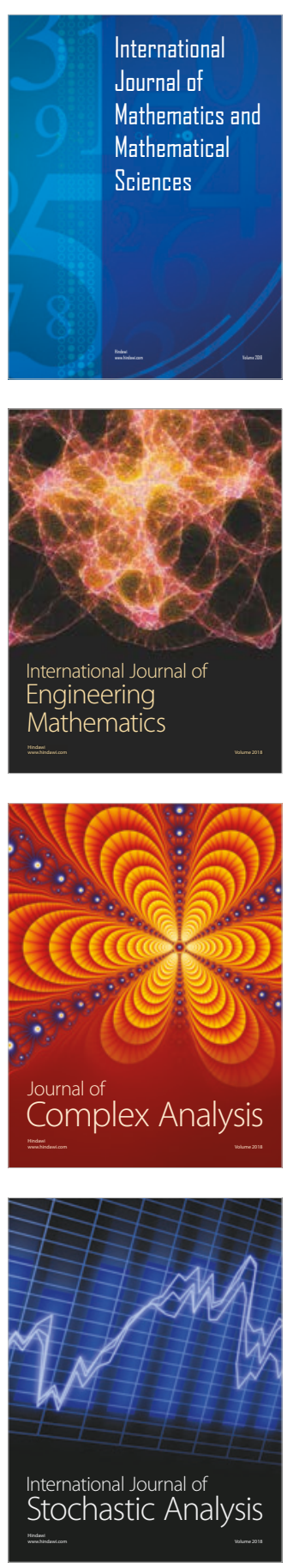
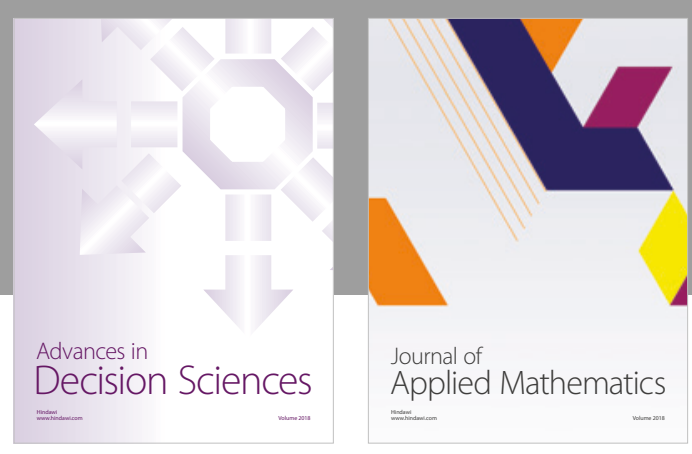

Journal of

Applied Mathematics
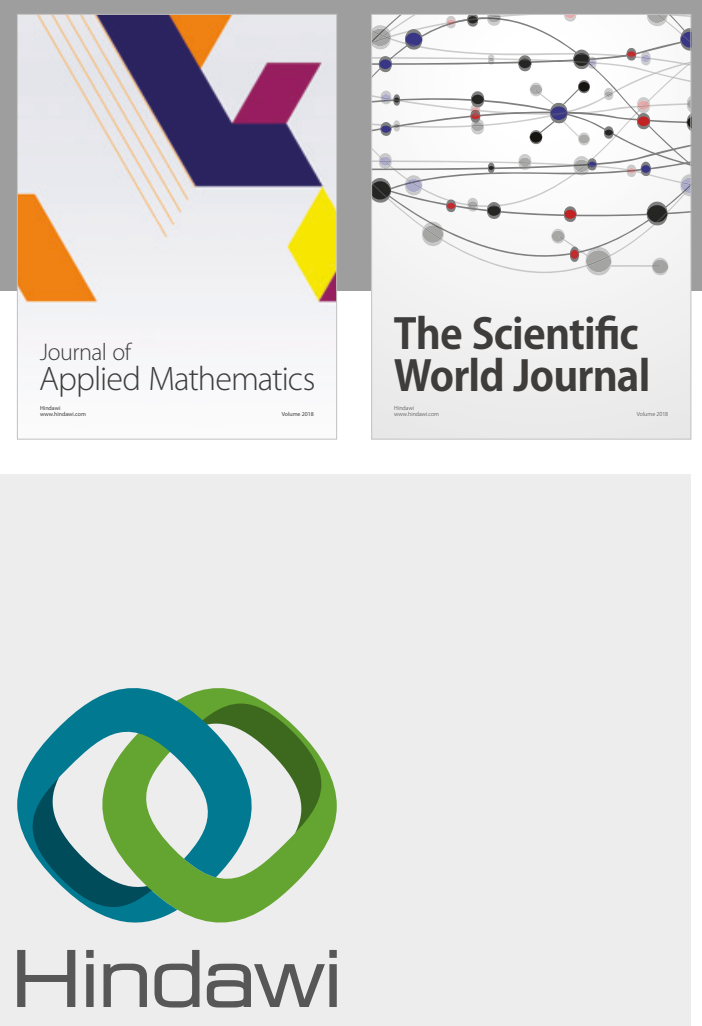

Submit your manuscripts at

www.hindawi.com

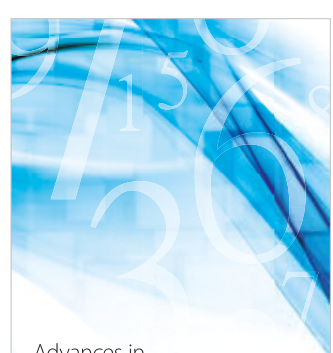

Advances in
Numerical Analysis
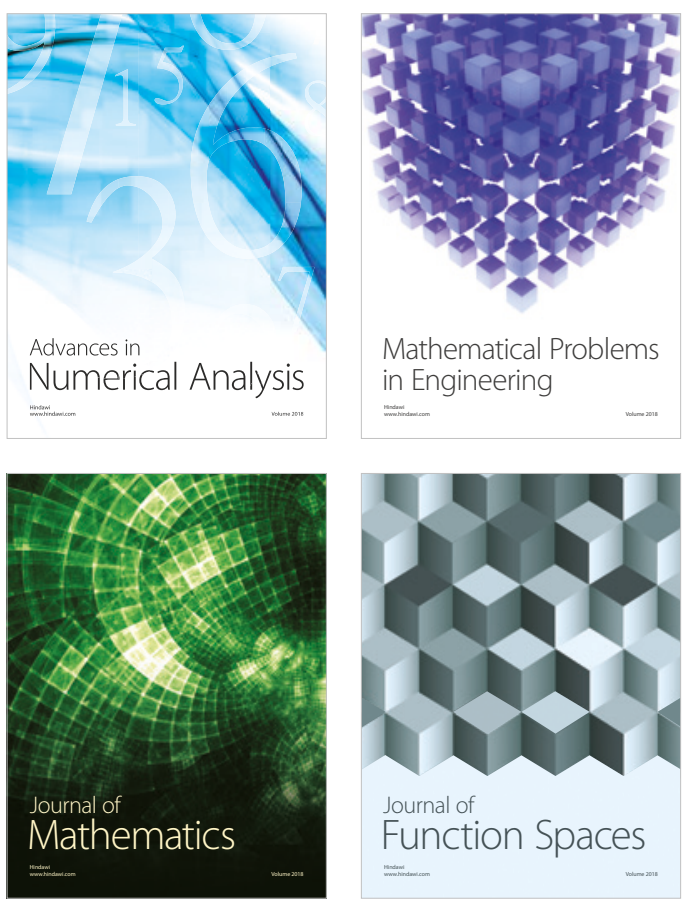

Mathematical Problems in Engineering

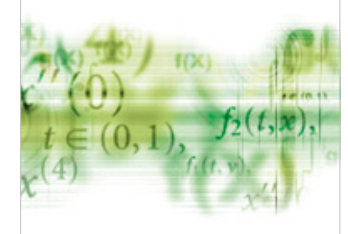

International Journal of

Differential Equations

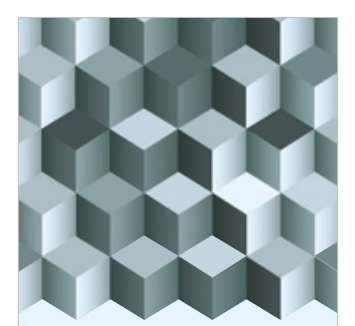

Journal of

Function Spaces
The Scientific

World Journal

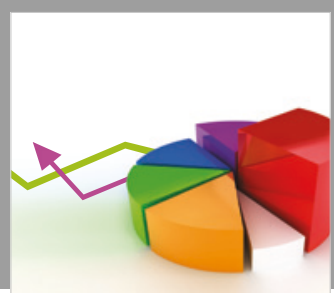

Journal of

Probability and Statistics
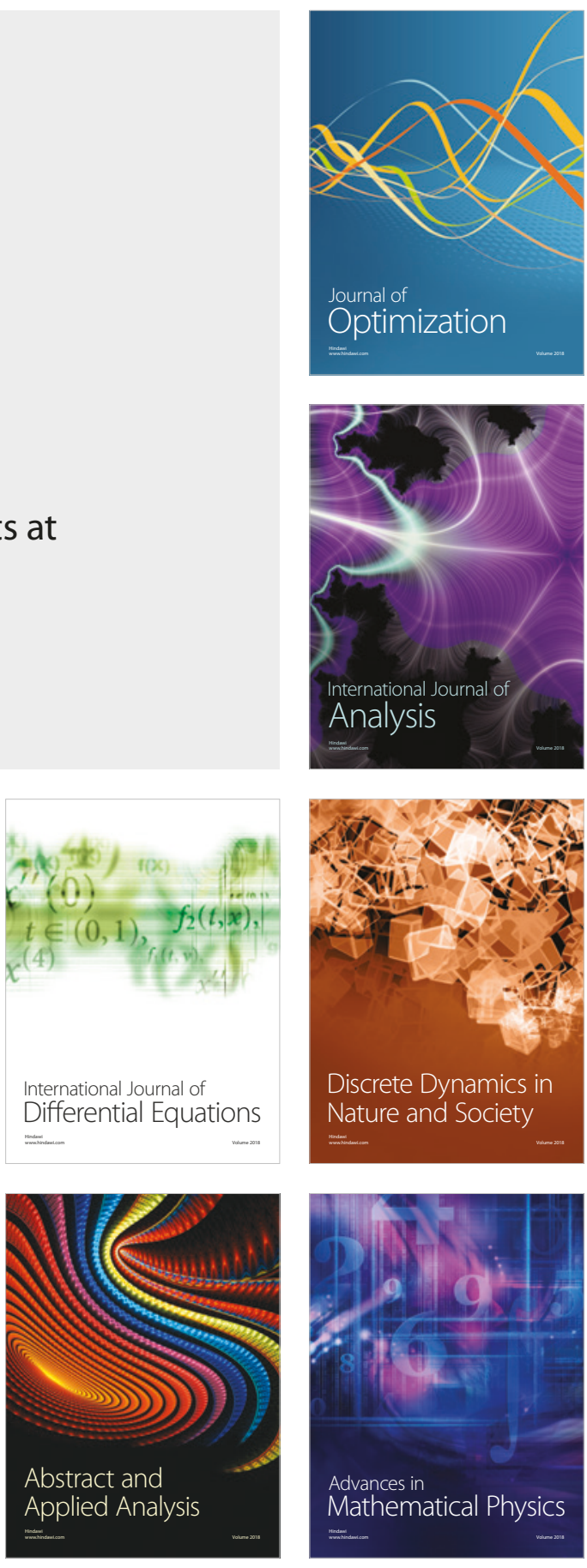